\title{
A NOVA LEI DE MIGRAÇÃO NA SOCIEDADE BRASILEIRA
}

\author{
THE NEW MIGRATION LAW IN BRAZILIAN SOCIETY
}

Carlos Alberto Leite

Mestre em Politicas Públicas e em Direitos Humanos pela Universidade Federal do Rio de Janeiro

Servidor do Estado

vsml62@hotmail.com

Victória Sarmento Mitre Leite

Graduanda em direito pela Universidade Cândido Mendes

vicksarmento21@gmail.com

\section{RESUMO}

A Nova Lei de Migração foi internalizada no Estado brasileiro em 24 de maio de 2017, substituindo o Estatuto do Estrangeiro de 1980. Entrou em vigor em 21 de novembro do mesmo ano. O objetivo deste artigo é publicizar o percurso da Nova Lei, destacando-se: forças sociais da sociedade que opinaram sobre a nova normativa; dialética de mitos versus verdades; avanços; desafios e sugestôes para dar maior efetividade à Nova Lei. A essência do referencial teórico fundamentalmente aponta para o fato de que a Nova Lei relaciona a imigração aos direitos humanos, portanto, afasta a antiga dimensão da segurança nacional. Como resultados, apresentam-se, entre outros: a omissão da lei em não especificar uma instituição líder que coordene a Política Migratória; necessidade de persistência para mitigar os inúmeros desafios, entre os quais, maior integração entre as administraçôes federal, estadual e municipal. A metodologia se apoia em uma pesquisa documental. A importância do artigo visa a contribuir com a Academia e gestores responsáveis pela Política Migratória.

Palavras- chave: Percurso. Mitos versus verdades. Avanços. Desafios. Sugestóes.

\section{ABSTRACT}

The New Migration Law was internalized in the Brazilian State on May 24, 2017, re- 
placing the Foreign Statute of 1980. It entered into force on November 21 of the same year. The aim of this article is to publicize the path of the new law, highlighting, among others: the social forces of society that opined on the new normative; dialectic of myths versus truths; advances; challenges; and suggestions to make the New Law more effective. The essence of the theoretical framework fundamentally points to the fact that the New Law relates immigration to human rights, thus, moving away from the old dimension of national security. As a result, we present, among others: the omission of the law in not specifying a leading institution that coordinates the Migration Policy; need persistence to mitigate the many challenges, including greater integration between federal, state and municipal administrations. The methodology is based on a documentary research. The importance of the article aims to contribute to the Academy and managers responsible for Migration Policy.

Keywords: Path. Myths versus truths. Advances. Challenges. Suggestions.

Data de submissão: 04/09/2019

Data de Aceitação: 19/03/2020

\section{SUMÁRIO}

INTRODUÇÃO 1. PERCURSO DA NOVA LEI 2. MITOS VERSUS VERDADES 3. AVANÇOS 4. DESAFIOS 5. SUGESTÓES. CONSIDERAÇÓES FINAIS.

\section{INTRODUÇÃO}

A nova Lei de Migração de 2017 foi uma necessidade decorrente do amadurecimento da sociedade e do Estado brasileiros na medida em que o antigo Diploma do Estrangeiro de 1980 não atendia mais aos anseios vigentes, nessa dimensão, o novo marco normativo representa ${ }^{1}$ substancial mudança de enfoque com ênfase na garantia dos direitos das pessoas migrantes: estrangeiros que por aqui aportam e para os brasileiros que vivem no exterior.

Nessa perspectiva inovadora de mudanças, no primeiro capítulo serão publicizados os seguintes tópicos: a participação das diversas forças sociais na propositura do novo marco regulatório, com suas respectivas propostas; no segundo capítulo, mitos e verdades, tratar-se -á desse embate dialético que envolveu a formação da lei; em seguida, no terceiro capítulo,

OLIVEIRA, Antônio Tadeu Ribeiro de. Nova lei brasileira de migraçáo: avanços, desafios e ameaças. R. bras. Est. Pop., Belo Horizonte, v. 34, n.1, p.171-179, jan./abr. 2017. 
mostrar-se-á o que a lei incorporou de avanços para os migrantes, sobretudo na perspectiva de direitos humanos; no quarto capítulo, visou-se a mostrar as inúmeras dificuldades que, de início, o novo marco regulatório se deparou; já no quinto capítulo, diversos atores da sociedade propuseram sugestôes, ideias, para que a Nova Lei nascesse com fôlego na sociedade brasileira; e, por último, realizadas as consideraçóes pessoais deste autor.

\section{PERCURSO DA NOVA LEI}

$A b$ initio, até a edição da Lei 13.445 , a matéria relativa à situação jurídica do estrangeiro tinha previsão pela Lei n. 6. 815, de 19 de agosto de 1980, portanto, não vigia uma lei que tratasse especificamente das migraçôes ${ }^{2}$.

A antiga Lei do Estrangeiro foi concebida nos governos militares com escopo na segurança nacional, nos interesses socioeconômicos do Brasil e do trabalhador nacional, portanto, a realidade nacional exigia nova Lei de Migraçáo, em face de obsolescência daquele Estatuto.

Em vista disso, a proposta de uma nova Lei Migratória trouxe o apelo a que se considerasse a necessidade de tratar da temática dos brasileiros no exterior como um tema sobre o qual é necessário que se formulem políticas públicas e as previsóes legais que as assegurem e efetivem ${ }^{3}$.

Nesse sentido, o Ministério da Justiça ${ }^{4}$, por meio da Portaria n ${ }^{\circ}$ 2.162/2013, criou uma Comissão de Especialistas com a finalidade de apresentar uma proposta de Anteprojeto de Lei de Migraçóes e Promoção dos Direitos dos Migrantes no Brasil, e entre 25 de julho de 2013 e 30 de maio de 2014, a Comissão realizou sete reunióes presenciais das quais participaram representantes do governo, instituiçóes internacionais, parlamentares, especialistas e acadêmicos.

Desse modo, essa comissão elaborou o anteprojeto, em face de o antigo Estatuto do Estrangeiro proibir, entre outros ${ }^{5}$ o estrangeiro de exercer atividade de natureza política, além de permitir a expulsão do estrangeiro que atentasse contra a segurança nacional, a moralidade pública e a economia popular.

\footnotetext{
2 GUERRA, Sidney. Alguns aspectos sobre a situação jurídica do não nacional no Brasil: da lei do estrangeiro à nova lei de migração. Direito em Debate. Revista do Departamento de Ciências Jurídicas e Sociais da Unijuí. Ano XXVI n. 47. jan.-jun. 2017. p. 90-112.

3 MILESI, Rosita. Por uma nova Lei de Migraçôes: a perspectiva dos direitos humanos. In: GREGORI, José et al. ACNUR. Refúgio. Migrações e Cidadania. Caderno de Debates 2. Agosto de 2007. IMDH, 2007. p. 88.

4 COMISSÃO DE ESPECIALISTAS PARA ELABORAÇÃO DE ANTEPROJETO DE LEI DE MIGRAÇÓES E PROMOÇÃO DOS DIREITOS DOS MIGRANTES NO BRASIL- instituída pelo Ministério da Justiça pela Portaria n ${ }^{\circ}$ 2.162/2013. Relatório final. p. 2. Brasília, 31 de julho de 2014. p. 1-50. Disponível em: https://reporterbrasil.org.br/documentos/anteprojeto.pdf. Acesso em: 12 ago. 2019. O Projeto de Lei do Senado n 288, de 2013, que gerou a Lei de Migraçáo, foi de autoria do Senador Aloysio Nunes Ferreira.

5 BRASIL. Ministério da Justiça. Entenda o Anteprojeto de Lei de Migraçóes.
} 
Nessa direção, conforme Torelly, houve ampla participação de forças sociais, representadas por: sociedade civil, atores governamentais, organizaçóes internacionais, academia, iniciativa privada e associação de migrantes, as quais apresentaram propostas para tornar a futura Lei de Migração consentânea com os interesses da sociedade brasileira, sobretudo dos migrantes, razão de ser do novo marco regulatório, nessa perspectiva as forças sociais apresentaram as seguintes propostas ${ }^{6}$ :

Quadro 01: Atores/Propostas

\begin{tabular}{|l|l|}
\hline \multicolumn{1}{|c|}{ Atores } & \multicolumn{1}{c|}{ Propostas } \\
\hline 1. Sociedade Civil & $\begin{array}{l}\text { implementaçáo de políticas públicas particulares a migrantes e garantia } \\
\text { de acesso às políticas universais; estabelecimento de protocolos e normas } \\
\text { para atendimento (regularização documental e acesso a políticas públicas). }\end{array}$ \\
\hline $\begin{array}{l}\text { 2. Atores } \\
\text { Governamentais }\end{array}$ & $\begin{array}{l}\text { capacitação de servidores a atendimento de migrantes e refugiados; } \\
\text { regulamentação da organização dos fluxos e atribuição de competências. }\end{array}$ \\
\hline $\begin{array}{l}\text { 3. Organizaçóes } \\
\text { Internacionais }\end{array}$ & $\begin{array}{l}\text { necessidade de refletir sobre as fronteiras nacionais; estruturação de } \\
\text { uma política nacional para migrantes. }\end{array}$ \\
\hline $\begin{array}{l}\text { 4. Academia } \\
\text { implementação do novo arcabouço migratório acompanhado de ampla } \\
\text { revisão das políticas públicas que atualmente se limitam aos brasileiros. }\end{array}$ \\
\hline $\begin{array}{l}\text { 5. Iniciativa Privada } \\
\text { migrantes }\end{array}$ & $\begin{array}{l}\text { responsabilidade estatal em conferir os meios e a segurança jurídica } \\
\text { necessários a que a iniciativa privada possa comprometer-se com o tema. }\end{array}$ \\
\hline $\begin{array}{l}\text { garantia dos direitos humanos dos migrantes; combate à xenofobia; } \\
\text { Política migratória nacional estruturada. }\end{array}$ \\
\hline
\end{tabular}

Fonte: TORELLY, Marcelo (coord.) et al. Adaptado pelo autor do artigo.

Desse modo, a nova normativa apontaria para novo perfil, verbi gratia $(v \cdot g$. $)$ : mudança de paradigma na política migratória; abandono da tipologia "estrangeiro"; o termo "migrantes" inclui os brasileiros que deixam o país; incorporação de reivindicaçôes da sociedade civil como a criação de um órgão estatal centralizado a atendimento aos migrantes; e adaptação legislativa à realidade de mobilidade humana e globalização econômica ${ }^{7}$.

Nessa dinâmica, conforme Asano e Timo (2017, on-line), as organizaçóes da sociedade civil propuseram cinco açóes que sintetizam os princípios mínimos que a nova Lei de

\footnotetext{
6 TORELlY, Marcelo (coord.) et al. Visôes do Contexto Migratório no Brasil. Brasília: Organização Internacional para as Migraçôes, Agência das Naçôes Unidas para as Migrações, 2017. p. 78.

7 BRASIL. Ministério da Justiça. Entenda o Anteprojeto de Lei de Migraçóes.
} 
Migração deveria assentar-se, convergente com uma perspectiva dos direitos humanos:

1. A garantia dos direitos humanos das pessoas migrantes, sem discriminaçáo de nenhum tipo e independente da situação migratória.

2. O estabelecimento de procedimentos de regularização migratória rápidos, efetivos e acessíveis como uma obrigaçáo do Estado e um direito do imigrante.

3. A não criminalizaçẫo das migraçôes, incluindo o princípio de não detenção do imigrante por razóes vinculadas à sua situação migratória.

4. O controle judicial e o acesso dos imigrantes a recursos efetivos sobre todas as decisões do poder público que possam gerar vulneração de seus direitos.

5. A criação de uma instituição nacional autônoma, com um corpo profissional permanente e especializado e mecanismos de supervisão e controle social, responsável pela aplicaçáo da lei.

Ou seja, com a perspectiva de que o9 "horizonte a ser buscado é o da cidadania universal dos migrantes, configurada no conjunto de direitos inalienáveis, intrínsecos a todo ser humano", bem como a nova regulamentação deve possuir um leque de garantias mínimas, exempli gratia $(e . g .)^{10}$ : acesso ao devido processo legal para o solicitante de refúgio; não devolução; proibição de deportação em massa e de usar o argumento da entrada irregular para rejeição do pedido de refúgio; e impossibilidade de aceleraçáo do processo visando à negativa do pedido de refúgio.

Assim sendo, na visão de Torelly et al. $(2017, \text { p. } 45)^{11}$,

Nos últimos quatro anos, vários debates em torno das migraçóes foram impulsionados no Brasil, principalmente pela chegada de migrantes haitianos, que evidenciou uma série de questóes como: ausência de políticas públicas para o acolhimento, obstáculos burocráticos para se obter documentação, discriminaçáo e dificuldades de integraçáo. Essas e outras questôes foram dialogadas no âmbito de eventos públicos que problematizaram diversos pontos sensíveis que envolvem as migraçóes e buscaram soluçóes, incluindo a constataçáo coletiva sobre a necessidade de uma nova Lei de Migração em sintonia com o respeito aos direitos humanos.

\footnotetext{
8 ASANO, Camila Lissa. TIMO, Pétalla Brandão. A nova Lei de Migraçáo no Brasil e os direitos humanos, on-line. Rio de Janeiro, 17 abr. 2017.

9 MILESI, Rosita. Por uma nova Lei de Migraçóes: a perspectiva dos direitos humanos. In: GREGORI, José et al. ACNUR. Refúgio. Migraçôes e Cidadania. Caderno de Debates 2. Agosto de 2007. IMDH, 2007. p. 94.

10 TORELLY, Marcelo (coor) et al. Política de refúgio do Brasil consolidada. Brasília: Organização Internacional para as Migrações, Agência das Naçôes Unidas para as Migraçôes, 2017. p. 45.

11 ASANO, Camila Lissa. TIMO, Pétalla Brandão. A nova Lei de Migraçáo no Brasil e os direitos humanos, on-line. Rio de Janeiro, 17 abr. 2017.
} 
Nesse contexto, constataram-se duas realidades: o debate sobre ausência de políticas públicas e a necessidade de nova Lei de Migração, portanto, a ratio explícita que culminou na Lei Migratória.

Sim, a temática da ausência de políticas públicas ainda é um fato ${ }^{12}$, pois

A Lei não está totalmente de acordo com a realidade e necessidades dos imigrantes, o Poder Público ainda se mostra ineficiente para atuar nessas questôes, e a sociedade ainda está alheia a tudo isso com informaçôes equivocadas a respeito de migraçôes (NOVO, 2018, on-line).

\section{MITOS VERSUS VERDADES}

Este capítulo tem por escopo analisar o quadro proposto por Delfim (2019), no qual a Nova Lei de Migração foi cercada por mitos e verdades ${ }^{13}$ :

Quadro 02: Mitos versus Verdades

\begin{tabular}{|l|l|}
\hline \multicolumn{1}{|c|}{ MITOS } & \multicolumn{1}{c|}{ VERDADES } \\
\hline $\begin{array}{l}\text { 1. Com a nova lei, o } \\
\text { país será invadido por } \\
\text { estrangeiros. }\end{array}$ & $\begin{array}{l}\text { Nada indica que o Brasil se tornará um destino prioritário a } \\
\text { migrantes e refugiados. Segundo dados da ONU, há atualmente } \\
\text { mais de 240 milhóes de pessoas vivendo fora de seu país de origem } \\
\text { - dois terços delas estáo na Europa e na Ásia. }\end{array}$ \\
\hline $\begin{array}{l}\text { 2. A entrada de } \\
\text { migrantes aumentará a } \\
\text { criminalidade }{ }^{14} \text {. }\end{array}$ & $\begin{array}{l}\text { Não há evidência de que os migrantes se envolvam mais em crimes } \\
\text { que os brasileiros. }\end{array}$ \\
\hline $\begin{array}{l}\text { 3. A lei deixará o país } \\
\text { mais vulnerável ao } \\
\text { terrorismo. }\end{array}$ & $\begin{array}{l}\text { É equivocado e xenofóbico pressupor que os migrantes são } \\
\text { um risco à segurança nacional. A posição viola o princípio } \\
\text { constitucional da presunção de inocência. }\end{array}$ \\
\hline
\end{tabular}

Fonte: DELFIM, Rodrigo Borges. Adaptado pelo autor do artigo.

No tocante ao item 1, o autor pontua como verdade que não há indícios no sentido de o País tornar-se porto seguro para migrantes, no entanto, em face da crise na Venezuela, a

12 NOVO, Benigno Núńez. Migraçáo na visáo da nova lei, on - line. Brasília-DF: 03 abr. 2018.

13 DELFIM, Rodrigo Borges. Nova Lei de Migraçáo: Mitos versus verdade. MigraMundo, on-line. São Paulo, 18 abr. 2017.

14 Moulin e Santoro elencam também como mito o fato de que: "os refugiados são foragidos da lei, estão fugindo porque cometeram crimes ou fizeram algo de errado em seus países". MOULIN, Carolina; SANTORO, Maurício. Três mitos sobre refugiados. Observatório do amanhã, on-line. Rio de Janeiro. 
imigração, particularmente em Roraima, tem sido intensa, pois, em função da Operação Acolhida - Política de interiorização dos venezuelanos a cargo do Exército brasileiro -, "desde que a operação se fixou em Boa Vista, mais de 12 mil imigrantes já foram interiorizados, para atender a demanda do constante fluxo de refugiados oriundos da Venezuela"15.

Ademais, segundo o Departamento de Polícia Federal (DPF), nos últimos 8 anos, o Brasil recebeu 206. 737 solicitaçôes de reconhecimento da condição de refugiado, passando de 3 . 538 pedidos, em 2011, para 80.057 solicitações em $2018^{16}$, ou seja, os números são assustadores, no entanto ${ }^{17}$, o país é o $5^{\circ}$ país latino-americano que recebe mais venezuelanos (168 mil), atrás de Colômbia (1,3 milhão), Peru (768 mil), Chile (288 mil) e Equador (263 mil).

Nesse sentido, por enquanto, há que se concordar com Delfim, pois não existem, até o presente momento, dados que comprovem que o país será um destino prioritário a migrantes e refugiados.

Em relação ao item 2, em Roraima, fruto de informaçóes obtidas em 2017,

[...] a não absorção do mercado de trabalho e a necessidade de sobrevivência dos migrantes venezuelanos têm refletido na segurança pública roraimense, pois tem aumentado de forma significativa a incidência de ilícitos praticados por venezuelanos. O índice de crimes cometidos por venezuelanos tem aumentado muito desde 2014 e em números estatísticos revela um número exato de $212 \%$ de infratores e vítimas venezuelanas $[\ldots]^{18}$ (grifo nosso).

Conforme o Relatório das Violaçóes de Direitos contra Imigrantes Venezuelanos no Brasil, do Conselho Nacional dos Direitos Humanos, no mês de Janeiro de 2018, "a DPU não identificou aumento do número de crimes cometidos por venezuelanos"19, mas $^{20}$, "um ano após violentos protestos contra a presença de venezuelanos em Pacaraima (RR), algumas dezenas de moradores brasileiros organizaram" manifestaçóes para maximizar a segurança e organização na cidade fronteiriça, e nos dois últimos anos foram registradas quase seis mil ocorrências com envolvimento de estrangeiros, a maioria venezuelanos, uma vez que:

Roraima verificou um grande aumento no número de crimes cometidos por imigrantes, em sua maioria venezuelanos, segundo relatório

\footnotetext{
15 BRASIL. Ministério da Defesa. Operaçáo Acolhida: mais de 12 mil imigrantes já foram interiorizados, on-line. Brasília, 18 jun. 2019.

16 BRASIL. Ministério da Justiça e Segurança Pública. Refúgio em Números, 4a Edição. 2019, p. 22.

17 Número de refugiados e migrantes da Venezuela chega a 4 milhôes. Agência Brasil, EBC, on-line. 07 jun. 2019. Disponível em: http://agenciabrasil.ebc.com.br/internacional/no. 07 jun. 2019.

18 EVANGELISTA, Rodrigo Luiz Soares. Os reflexos da imigração Venezuelana: perfil dos imigrantes, Segurança Pública e Saúde Pública. O defesanet, 2017, on-line. Brasília, 19 dez. 2017.

19 CONSELHO NACIONAL DOS DIREITOS HUMANOS (CNDH). Relatório das violaçóes de direitos contra imigrantes venezuelanos no Brasil. Jan. 2018, p 1- 41. Brasília, Maio 2018.

20 MAISONNAVE, Fabiano. Protesto em Roraima pede mais ordem na fronteira e assusta venezuelanos. Folha de Sáo Paulo, on-line. Sáo Paulo, 17 ago. 2019.
} 
estatístico do Centro Integrado e Operações Policiais da Secretaria Estadual da Segurança Pública (grifo nosso). ${ }^{21}$

Portanto, os fatos apontam que a entrada de migrantes venezuelanos em Roraima vem aumentando a criminalidade, nessa toada, particularmente nesse estado, o mito 1 se aproxima muito mais de uma verdade do que uma ficção propriamente dita, no entanto, no restante do país não há sólidas evidências no sentido de que a entrada de migrantes vem aumentando a criminalidade.

No que diz respeito ao item 3, houve preocupaçóes reverberadas nas mídias sociais, pois, conforme a Diretoria de Análises de Políticas Públicas da FGV/RJ:

[...] 60, 5 mil tweets sobre o tema entre 17 de abril e 25 de maio de 2017, período entre a aprovaçáo do projeto de lei pelo Senado e a sanção presidencial. Há uma clara manifestação de mensagens em torno da lei, com maior coesão entre aqueles que exigem que Temer vete o projeto antes que haja uma entrada massiva de "terroristas, comunistas e traficantes" (grifo do autor) ${ }^{22}$.

À vista do exposto, passados mais de dois anos da aprovação da Lei de Migração, não há dados que comprovem que entraram no país "terroristas, comunistas e traficantes", ademais, comparando-se com o Estatuto do Refugiado, Lei 9. 474 de 22 de julho de 1997, que completou 20 anos em 2019, sem a configuração de casos de refugiados que percorreram o caminho do terrorismo ao longo desse recorte temporal, nesse rumo, a tese de que a lei deixará o país mais vulnerável ao terrorismo se constitui em um mito.

\section{AVANÇOS}

A Nova Lei veio a regular a situação jurídica do estrangeiro no país ${ }^{23}$ : os direitos e deveres do migrante e do visitante no Brasil; entrada e permanência de estrangeiros; estabeleceu normas de proteção ao brasileiro no exterior e modificações na nomenclatura do não nacional, substituindo a figura do estrangeiro para a do migrante, à luz do artigo $1^{\circ}, \$ 1^{\circ}$. Ademais, permite-lhes exercer cargo, emprego e função pública, excetuados os destinados a brasileiro nato (art. $12, \$ 3$ da CF), não lhe sendo exigível prova documental impossível que obste o exercício dos direitos, acesso a cargo, emprego ou função pública.

\footnotetext{
21 RODRIGUES, Edílson. RR sofre com o aumento de crimes cometidos por imigrantes. Folha de Boa Vista, on-line. Boa Vista, 16 dez. 2019.

22 FUNDAÇÃO GETÚlIO VARGAS. Diretoria de Análise de Políticas Públicas (DAPP). O Debate sobre a Lei de Migraçáo, on-line. Rio de Janeiro, 26 maio 2017, p. 1-16.

23 GUERRA, Sidney. A nova lei de migração no brasil: avanços e melhorias no campo dos direitos humanos. Revista de Direito da Cidade, vol. 09, n. 4. ISSN 2317-7721, pp. 1717-1737.
} 
Em relação ao Estatuto do Estrangeiro, a Lei de Migração possui diferenças, entre outras $^{24}$ : enquanto o antigo Estatuto "usa os termos estrangeiros e alienígenas", a nova Lei "usa o termo migrantes (imigrantes e emigrantes)", ou seja ${ }^{25}$, abandonou-se o termo "estrangeiro", excluindo estigmas em relação ao imigrante e reconhecendo a condição humana de ser imigrante, portador de direitos e deveres fundamentais, bem como considera estrangeiro quem, conforme as regras jurídicas do Estado em que se encontra, náo integra o conjunto dos nacionais desse Estado ${ }^{26}$.

Nesse sentido ${ }^{27}$, para obter a condição de estrangeiro, é necessário somente que a pessoa se locomova da jurisdiçáo do Estado a que pertença e passe à jurisdição de outro, sem integrar a totalidade dos nacionais desse Estado.

Mas, no contexto dos avanços que a Nova Lei representa para o Estado ${ }^{28}$ :

não obstante alguns vetos inspirados em visóes que defendem medidas restritivas, o país passa a ter uma das legislaçóes mais modernas no trato das políticas migratórias, avançando no tratamento dos pilares que sustentam a integração plena do migrante à sociedade brasileira ao assegurar o pleno acesso aos serviços, garantindo a reuniâo familiar, reconhecendo a formaçáo acadêmica obtida no exterior, permitindo a associação sindical e política, facilitando a inclusão laboral, repudiando práticas de discriminação e descriminalizando a migraçẫo e repudiando práticas de deportaçóes coletivas (grifo nosso).

De igual modo:

No plano da cooperação internacional, apesar de o país já possuir uma legislação moderna na questão do refúgio - a Lei n. 9.474/1997 [...] e já vir adotando políticas de acolhimento humanitário, como no caso dos haitianos, ter incluído expressamente na nova lei o dispositivo que permite a concessão desse tipo de visto foi fundamental. Ademais, a facilitação das remessas, a proteção aos brasileiros residentes no exterior, a cooperação com os Estados de origem, trânsito e destino buscando a proteção dos direitos do migrante e o fortalecimento da integração econômica, política, social e cultural dos povos da América Latina são medidas protetivas importantíssimas e que fazem com que avance o trato das questóes migratórias nas relaçôes com os demais países en-

24 Idem.

25 REDIN, Giuliana. Direito Humano de Imigrar e os desafios para construção de uma política nacional para imigrantes e refugiados. In: REDIN, Giuliana; SALDANHA, Jânia Maria Lopes; SILVA, Maria Beatriz Oliveira da. Direitos Emergentes na Sociedade Global: PPG em Direito na UFSM. Santa Maria: UFSM, 2016. p. 18.

26 Tibúrcio, apud MAZZUOLI, Valério de Oliveira. Curso de Direito Internacional Público. 6a ed. São Paulo: Revista dos Tribunais, 2012. p. 720.

27 MAZZUOLI, Valério de Oliveira. Curso de Direito Internacional Público. 6a ed. São Paulo: Revista dos Tribunais, 2012. p. 720. A expressão “da jurisdição do Estado a que pertença” significa do Estado do qual se é nacional, caso a pessoa tiver uma nacionalidade, ou de qualquer Estado, se for apátrida.

28 OLIVEIRA, Antônio Tadeu Ribeiro de. Nova lei brasileira de migração: avanços, desafios e ameaças. R. bras. Est. Pop., Belo Horizonte, v. 34, n.1, p.171-179, jan./abr. 2017. 
volvidos nessa temática. $^{29}$

Destacam-se outros avanços ${ }^{30}:$ o estrangeiro em situação irregular no país não poderá ser preso; desburocratização do processo de regularização migratória; anistia os que já se encontram em território nacional; princípio do contraditório e ampla defesa; garantia ${ }^{31}$ de acesso à assistência judiciária gratuita, com atuação obrigatória da Defensoria Pública em casos de detenção ${ }^{32}$ de migrantes nas fronteiras, inviabilizando a deportação imediata realizada pelo DPF; $\mathrm{o}^{33}$ náo esquecimento do brasileiro que está no exterior ao tratar da necessidade da adoção de uma política pública de apoio ao cidadão que se encontra no exterior.

No tocante à anistia, trata-se de perdáo por parte do Estado visando a possibilitar a regularização migratória, sem penalidades, aos estrangeiros que residem no país de forma irregular, desse modo, é sempre vista pelos imigrantes como uma esperança de sair da condição de indocumentados ou da clandestinidade, livrando-se da exploraçấo a que ficam sujeitos quando não têm a necessária documentação ${ }^{34}$.

Assim sendo ${ }^{35}$, no dia 13 de junho de 2017, antes da sançáo presidencial da nova Lei de Migração e do veto à anistia, foi apresentado à Câmara dos Deputados o Projeto de Lei n. ${ }^{\circ} 7.876 / 2017$, propondo a concessáo da quinta anistia para migrantes no Brasil, cuja redação vetada pelo Presidente Temer, no Projeto de Lei 288/2013, foi adaptada de modo a superar as razóes do veto.

Quanto à regularizaçáo de documentação, outro avanço ${ }^{36}$ :

A lógica da nova lei é contrária à anterior, que impedia a mudança de categoria estando no país. Era uma lógica de controle, de segregaçăo: difícil mudar de categoria estando no país. Com a nova lei, estão abarcadas as questôes dinâmicas da vida. A nova lei é flexível. É uma mudança positiva: possibilidade de documentar estando no país. Isso tira a pressão sobre o mecanismo do refúgio.

$\mathrm{Na}$ perspectiva do trabalho ${ }^{37}$, ficam garantidos o mercado de trabalho e direito à previ-

29 OLIVEIRA, Antônio Tadeu Ribeiro de. Nova lei brasileira de migração: avanços, desafios e ameaças. R. bras. Est. Pop., Belo Horizonte, v. 34, n.1, p.171-179, jan./abr. 2017. p.175

30 CASTRO, Carolina. Migraçáo: nova lei assegura direitos e combate a discriminaçáo.

31 NOVO, Benigno Núñez. Migraçáo na visáo da nova lei.

32 O autor se refere ao Instituto da deportação, à luz do art. 50: "A deportação é medida dec+orrente de procedimento administrativo que consiste na retirada compulsória de pessoa que se encontre em situação migratória irregular em território nacional".

33 RAMOS, André de Carvalho. Os avanços da nova Lei de Migração. Jornal da USP. São Paulo, 22 maio 2017.

34 INSTITUTO MIGRAÇÓES E DIREITOS HUMANSO (IMDH). Glossário. Brasília, 31 jan. 2014.

35 DEFENSORIA PÚBLICA DA UNIÃO (DPU). Uma introdução às migraçôes internacionais no Brasil contemporaneo. Módulo 2, p. 23.

36 TORELLY, Marcelo (coord.) et al. Visóes do Contexto Migratório no Brasil. Brasília: Organização Internacional para as Migraçóes, Agência das Naçóes Unidas para as Migraçóes, 2017. p. 51.

37 BARZOTTO, Luciene Cardoso. Nova lei da imigraçáo no Brasil: o trabalhador estrangeiro diante do 
dência social, bem como há convergência com a OIT, posto que editou a Convenção 143, a qual prevê a proteção trabalhista dos imigrantes mediante garantias de direitos humanos no acesso à ocupação produtiva justa e na restrição à exploração abusiva na sua prestação de serviços, no sentido de favorecer as interaçóes laborais, econômicas e sociais, valorizando direitos e realçando o contributo do imigrante na construção na comunidade nacional.

A gestão da entrada de migrante no país é, principalmente, de responsabilidade dos Ministérios das Relaçōes Exteriores, da Justiça e Departamento de Polícia Federal, e do Trabalho, os quais ${ }^{38}$

devem praticar em conjunto uma série de deliberaçóes a respeito da concessão de residência, entre outras, para as seguintes situaçóes: reunificação familiar; atividade de relevância econômica, científica, tecnológica ou cultural; interesses da política migratória nacional; proteção ao apátrida, refúgio ou asilo político, estabelecer os termos para determinação da condição de vulnerabilidade para fins de reconhecimento de hipossuficiência econômica.

Nesse sentido, a Lei e o Decreto 9. 199/2017 ${ }^{39}$ estabeleceram a competência legal do Ministério do Trabalho à autorização de residências para fins laborais. Assim, o imigrante que deseje ingressar no país para trabalhar, independente de vínculo empregatício, salvo exceçôes, necessita de residência a essa finalidade (residência prévia a efeito de concessáo de visto temporário ou residência ao que já se encontra no país), junto à Coordenaçẫo Geral de Imigração, e atender às Resoluções Normativas editadas pelo CNIg. Ademais, o visto é emitido pelo MRE que se traduz em uma expectativa de direito ao interessado de ingressar no Brasil.

O novo marco migratório deve assentar-se no fato de que ${ }^{40}$ :

o corpo jurídico internacional de proteção aos refugiados é determinado pela interação dialógica e complementar das normas do Direito Internacional de Refugiados, do Direito Internacional dos Direitos Humanos e do Direito Internacional Humanitário. Esses direitos são reconhecidos a todas as pessoas, nấo somente aos nacionais dos Estados membros. As pessoas que não são nacionais também são beneficiárias dos direitos garantidos nos instrumentos de direitos humanos, com limitadas exceçôes, como os direitos relativos à participação política. [...]

Por sua vez, o art. 77, com seis incisos, reverbera as Políticas Públicas com o desiderato

paradigma constitucional - fraternal. Disponível em: http://www.editorajc.com.br/nova-lei-da-imigracaono-brasil-o-trabalhador-estrangeiro-diante-do-paradigma-constitucional-fraternal/. Acesso em: 20 ago. 2019.

38 MINISTÉRIO DO TRABALHO. Coordenadoria Geral de Imigração (CGIg). $2^{\circ}$ Trimestre 2018 (AbrJun). Autorizaçóes de residência concedidas a imigrantes. Disponível em: http://obmigra.mte.gov.br/ index.php/relatorios-cgig-e-cnig. Acesso em: 20 ago. 2019.

39 Idem.

40 Cf. ACNUR, em seus comentários ao PL de Migração n. 2.516/15. Brasília, 2015b apud TORELLY, Marcelo (coor) et al. Política de refúgio do Brasil consolidada. Brasília: Organizaçáo Internacional para as Migraçôes, Agência das Naçôes Unidas para as Migrações, 2017. p. 33. 
de atender aos princípios e diretrizes, entre outros: promoção de condições de vida digna, a facilitar o registro consular e a prestação de serviços consulares nas "áreas de educação, saúde, trabalho, previdência social e cultura” (art. 77, II).

Nesse sentido, a nova Lei complementa o Estatuto do Refugiado de 1997, pois, à luz do artigo 121, "devem ser observadas as disposições da Lei 9. 474 [...], nas situações que envolvam refugiados e solicitantes de refúgio".

\section{DESAFIOS}

Os principais desafios se traduziram na regulamentação da Lei e o enfrentamento dos vetos da Presidência da República. Nesse sentido, os vetos foram, entre outros: a definição de migrante, pois o conceito estava ampliado ao incluir o imigrante, o emigrante, o residente fronteiriço e o apátrida (inciso I do $\$ 1^{\circ}$ do art. $1^{\circ}$ ); e o que impedia a revogação das expulsóes decretadas antes de 1988 também sob o argumento de que afetaria a soberania nacional ${ }^{41}$.

A centralidade da ratio do veto ao inciso acima assenta-se no fato de que o "dispositivo estabelece conceito demasiadamente amplo de migrante, abrangendo inclusive o estrangeiro com residência em país fronteiriço", ou seja, estende-se a qualquer estrangeiro, independente da situação migratória, a isonomia com os nacionais, violando o art. $5^{\circ} \mathrm{da}$ CF, posto que "aquela igualdade é limitada e tem como critério para sua efetividade a residência do estrangeiro no território nacional”, conforme a Mensagem no 163, de 24 de maio de $2017^{42}$.

Nessa dinâmica, segundo Oliveira, os vetos do Ministério da Justiça, da AGU e do GSI revelam ${ }^{43}$ contradiçôes e disputas entre setores do governo que "consideram as migrações uma questão de segurança, daí o discurso da soberania nacional", nesse sentido, "veem no migrante uma ameaça ao mercado de trabalho dos nacionais", demarcando-se uma "preocupação exacerbada com segurança e controle".

Ademais, outro desafio, segundo o Procurador do Estado de Roraima, Edival Braga:

"Essa política do governo federal de fronteiras abertas, sem ter uma política pública efetiva que possibilite aos imigrantes ou refugiados viver de forma digna, termina sendo aquele tipo de coisa que o Brasil acena no cenário internacional estar cumprindo os direitos humanos quando na verdade ele está descumprindo os direitos humanos" (grifo nosso). ${ }^{44}$

\footnotetext{
${ }^{41}$ OLIVEIRA, Antônio Tadeu Ribeiro de. Nova lei brasileira de migração: avanços, desafios e ameaças. R. bras. Est. Pop., Belo Horizonte, v. 34, n.1, p.171-179, jan./abr. 2017.

42 Disponível em: https://presrepublica.jusbrasil.com.br/legislacao/462557907/mensagem-163-17. Acesso em: 22 ago. 2019.

43 OLIVEIRA, Antônio Tadeu Ribeiro de. Nova lei brasileira de migração: avanços, desafios e ameaças. R. bras. Est. Pop., Belo Horizonte, v. 34, n.1, p.171-179, jan./abr. 2017.

44 SCHREIBER, Mariana. Grave crise em Roraima justifica fechamento da fronteira? Entenda os
} 
Sob outro olhar, Beto Vasconcelos, antigo presidente do Comitê Nacional para os Refugiados (CONARE), embora reconheça o empenho inicial do governo federal, mas tece críticas sobre a resistência em alocar mais recursos financeiros ao Estado em momento de crise, bem como "também repudia a postura do governo de Roraima que, na sua visão, incentiva a xenofobia (ódio ao estrangeiro)" ${ }^{45}$.

O sistema público de saúde tem sofrido reflexos com a imigração venezuelana, pois "de 2014 até agosto de 2017, o número de atendimento a venezuelanos mais que duplicou. [...] o número de atendimentos a venezuelanos teve um aumento de $247 \%{ }^{\text {" } 46}$, ou seja, configura-se mais um desafio a ser superado.

Outra adversidade repousa no fato de que ${ }^{47}$, mesmo se considerando que o novo marco migratório é avançado, em função de propiciar um rol mais denso de direitos aos imigrantes, e não os criminalizando, mas o fato é que "estabelece uma extensa burocracia para a regularização, bem como multas e penalidades àqueles que violarem a lei” (CULPI, 2017).

$\mathrm{Na}$ nossa exegese, a burocracia ainda é uma realidade que precisa ser mitigada, pois a faceta burocrática está no $D N A$ cultural, no modus vivendi nacional, portanto, de difícil remoção, posição sustentada pelo Banco Mundial: "Brasil é o país mais burocrático do mundo" 48 .

Outra ${ }^{49}$ dificuldade a ser enfrentada é a crescente manifestação organizada de segmentos sociais, contrários à nova lei, pois são pessoas equivocadas a respeito das migraçóes internacionais na medida em que a migração traz mais benefícios do que prejuízos para os países de destino, semelhantemente ${ }^{50}$, o modelo de inserção do imigrante na economia nacional ocorre na maioria das vezes com pouco grau de fraternidade, haja vista sua situação de vulnerabilidade - falta de acesso à educação formal, desconhecimento do idioma falado no novo país e dos seus direitos, - o imigrante é mais suscetível a ser empregado em condiçôes de descumprimentos dos seus direitos trabalhistas, redundando, em casos mais graves, na prática de trabalho forçado.

De igual modo, a questão migratória é recente para o país, trata-se de uma nova experiência, mas o novo marco trará um significativo impulso no sentido de que suas açóes se

argumentos contra e a favor. BBC, NEWS Brasil, on-line. Brasília, 22 ago. 2018.

45 SCHREIBER, Mariana. Grave crise em Roraima justifica fechamento da fronteira? Entenda os argumentos contra e a favor. BBC, NEWS Brasil on-line. Brasília, 22 ago. 2018.

46 EVANGELISTA, Rodrigo Luiz Soares. Os reflexos da imigraçáo Venezuelana: perfil dos imigrantes, Segurança Pública e Saúde Pública.

47 CULPI, Ludmila Andrzejewski. Nova lei de migraçóes brasileira: inspiração no modelo da lei migratória argentina? 2017.

48 FENACOM. Brasil é o país mais burocrático do mundo, segundo Banco Mundial. Folha de Londrina (PR), on - line. 2 fev. 2018.

49 MOULIN, Carolina; SANTORO, Maurício. Três mitos sobre refugiados. Observatório do amanhá.

50 CORREIA, Carolina Simóes; BARZOTTO, Luciene Cardoso; MARTINS, Renata Duval. Nova lei da imigraçáo no Brasil: o trabalhador estrangeiro diante do paradigma constitucional - fraternal. 24 jan. 2018. 
desenvolvam nos diferentes níveis da administração nacional, no entanto, um aspecto a buscar-se:

\begin{abstract}
é uma maior integração entre as administraçóes federal, estadual, municipal ao abordar a questão migratória. Será necessário avançar. $O$ foco tem sido na esfera federal e não na municipal, embora seja na última o contato principal com o migrante (grifo nosso). ${ }^{51}$
\end{abstract}

Sim, a dificuldade de os órgãos públicos no País trabalharem com viés integrativo é estrutural, porque integrar-se envolve antes de tudo um eficaz esquema de planejamento, nesse rumo, o brasileiro não é afeto a planejamento, portanto, encetar políticas no longo prazo, fato comprovado no Novo Diploma Migratório brasileiro, pois "Não há definido um órgão específico para coordenar as açôes e estratégias da NLM" "s2, assim, fica difícil integrar União e entes federados a tratar da Política Migratória com eficácia.

Para o Presidente do Conselho Nacional de Imigração, a nova Lei e sua regulamentação, o Decreto no 9.199/2017, também trouxeram desafios para o Conselho Nacional de Imigração e para o Ministério do Trabalho ${ }^{53}$ : "não só em razão das novas atribuiçóes e competências, mas principalmente o oportunizar o avanço em temas de grande relevância para o País [...]”. Ou seja, os temas de interesse para o Brasil se referem à atração de mão de obra altamente qualificada, déficit profissional, capacidades estratégicas e investimento.

\title{
5. SUGESTÓES ${ }^{54}$
}

As sugestóes a seguir correspondem ao trabalho de campo de diversos atores: sociedade civil, atores governamentais, organizaçóes internacionais, iniciativa privada, academia e associaçóes de migrantes, que trabalharam em eixos temáticos que nortearam a coleta de informaçôes (migrantes de grupos vulneráveis, regularização documental, restriçóes de acesso, iniciativa privada e trabalho, políticas públicas e autoridade migratória).

Nesse prumo, em relação aos migrantes de grupos vulneráveis: capacitar os servidores públicos, em especial da $\mathrm{PF}$, a atender às populaçóes vulneráveis, mormente na chegada.

\footnotetext{
1 TORELLY, Marcelo (coord.) et al. Visóes do Contexto Migratório no Brasil. Brasília: Organização Internacional para as Migraçóes, Agência das Naçōes Unidas para as Migrações, 2017. p . 59.

52 LEITE, Carlos Alberto. Análise das Políticas Públicas para Refugiados no Brasil à luz da Nova Lei de Migração: um Estudo de Caso nas Áreas de Saúde, Trabalho e Educação na região metropolitana do Rio de Janeiro. 236 f. Dissertação (Mestrado em Políticas Públicas em Direitos Humanos) - Núcleo de Políticas Públicas em Direitos Humanos, Universidade Federal do Rio de Janeiro, Rio de Janeiro, 2019.

53 SILVA, Hugo Medeiros Gallo da. Imigração, vetor estratégico para o desenvolvimento e crescimento nacional. In: BRASIL. Presidência da República. Diálogos Estratégicos: migração e seus impactos na sociedade do século XXI. Vol 1, n. 4, Dez 2018. p. 14-17.

54 Cf. TORELLY, Marcelo (coord.) et al. Visóes do Contexto Migratório no Brasil. Brasília: Organização Internacional para as Migraçôes, Agência das Naçôes Unidas para as Migraçóes, 2017. p. 87- 88. As propostas foram retiradas do autor.
} 
Na dimensão das restriçóes de acesso, a preocupação é garantir assistência advocatícia ou da Defensoria Pública e atendimento, por parte dos servidores públicos, com um olhar humanista e não estritamente policial, no sentido de propiciar os direitos do migrante, entre eles, a presunçáo de inocência, o devido processo legal e a ampla defesa.

No tocante ao papel da iniciativa privada, sugere-se que as empresas assumam a sua responsabilidade social; aproveitem o potencial criativo dos migrantes; criem políticas endógenas a contratá-los; promovam cursos de português; incentivem a inclusão e coíbam o racismo.

Quanto à autoridade migratória, parte dos atores propóe a criação de uma estrutura nova e específica à questão de migraçóes (uma secretaria ou agência), e outra parte sugere consolidar a articulação entre os órgãos já existentes, no entanto, nessa particularidade, a lei não previu um órgão específico para coordenar a Política Migratória, a exemplo do Estatuto do Refugiado, que criou o Comitê Nacional para os Refugiados (CONARE).

As recomendaçóes gerais e específicas pontuam a necessidade de elaboração de cursos de capacitação no tema da migração a servidores públicos municipais, de forma a qualificar $\mathrm{o}$ atendimento considerando as suas especificidades; ademais, recomenda-se a capacitação em relação à Lei de Migração, tendo como públicos-alvos atores da sociedade que tenham capilaridade na rede para difusão das informaçôes.

\section{CONSIDERAÇÓES FINAIS}

A Nova Lei de Migração é uma realidade na qual as forças sociais e o próprio Estado brasileiro têm que fortalecê-la diariamente para torná-la minimamente efetiva, com a dinamicidade necessária para propiciar dignidade a esse outro que vem de fora, mas, por outro lado, a lei falha em não especificar uma instituição líder que coordene a Política Migratória com a coparticipação das outras instituiçôes dos entes federados, responsáveis pelos migrantes, com o desiderato de propiciar maior integração entre as administraçôes federal, estadual e municipal, portanto, a ausência de um órgão responsável pela Política Pública, perpassando todas as fases da Política, principalmente o monitoramento e avaliaçáa, constitui-se em um ponto cego da Nova Lei de Migração, sobretudo pelos reflexos que adviráo: falta de controle dos migrantes no país, ou seja, em última instância, asseverar com exatidão se estarão ou não sob o manto da dignidade da pessoa humana que a própria lei propóe.

\section{REFERÊNCIAS}

ALVIM, Roberta Pires. O trabalho da DPU na defesa dos direitos dos migrantes ve- 
nezuelanos. Disponível em: https://www.conjur.com.br/2018-nov-06/tribuna-defensoria-trabalho-dpu-defesa-direitos-migrantes-venezuelanos. Acesso em: 25 ago. 2019.

ARAÚJO, Igor Eduardo dos Santos; FETT, Priscila, ANNONI, Danielle. O papel da Defensoria Pública da União na efetivaçáo do acesso à justiça para os refugiados no Brasil. In: ANNONI, Danielle (Coord.). Direito Internacional dos Refugiados e o Brasil. Curitiba: Gedai/UFPR, 2018. p. 348-363.

ASANO, Camila Lissa. TIMO, Pétalla Brandão. A nova Lei de Migraçáo no Brasil e os direitos humanos, on-line. Rio de Janeiro, 17 abr. 2017. Disponível em: https:// br.boell.org/pt-br/2017/04/17/nova-lei-de-migracao-no-brasil-e-os-direitos-humanos. Acesso em: 14 ago. 2019.

BRASIL. Ministério da Justiça. Portaria n. 2. 209, 10 ago. 2004, DOU 154, 11 ago. 2004. Disponível em: http://portal.mj.gov.br/Estrangeiros/legislacao/Portaria\%20n\%C2\%BA\%202.209.pdf. Acesso em: 12 ago. 2019.

Ministério da Justiça. Entenda o Anteprojeto de Lei de Migraçóes. Disponível em: http://www.justica.gov.br/news/proposta-de-nova-lei-de-migracoes-deverasubstituirestatuto-criado-durante-a ditadura/entenda_novo_estatutoestrangeiro2.pdf. Acesso em: 12 ago. 2019.

Ministério da Defesa. Operaçáo Acolhida: mais de 12 mil imigrantes já foram interiorizados, on-line. Brasília, 18 jun. 2019. Disponível em: https://www.defesa. gov.br/noticias/57317-operacao-acolhida-mais-de-12-mil-imigrantes-ja-foram-interiorizados. Acesso em: 18 ago. 2019.

Ministério da Justiça e Segurança Pública. Refúgio em Números, 4a Edição. 2019, p. 1- 46. Acesso em: 20 dez. 2019.

CASTRO, Carolina. Migração: nova lei assegura direitos e combate a discriminação. Disponível em: https://www12.senado.leg.br/noticias/especiais/especialcidadania/migracao-nova-lei-assegura-direitos-e-combate-a discriminacao/. Acesso em: 19 ago. 2019.

COMISSÃO DE ESPECIALISTAS PARA ELABORAÇÃO DE ANTEPROJETO DE LEI DE MIGRAÇÓES E PROMOÇÃO DOS DIREITOS DOS MIGRANTES NO BRASIL: instituída pelo Ministério da Justiça pela Portaria $n^{\circ}$ 2.162/2013. Relatório final. Brasília, 31 de julho de 2014. p. 1-50. Disponível em: https://reporterbrasil.org.br/ documentos/anteprojeto.pdf. Acesso em: 12 ago. 2019.

CONSELHO NACIONAL DOS DIREITOS HUMANOS (CNDH). Relatório das violaçóes de direitos contra imigrantes venezuelanos no Brasil. Brasília. Maio 2018. Disponível em: https://www.conectas.org/wp/wp-content/uploads/2018/05/ relatorio-sobre-violacoes-de-direitos-humanos-contra-imigrantes-venezuelanos-1. pdf. Acesso em 18 ago. 2019.

CORREIA, Carolina Simóes; BARZOTTO, Luciene Cardoso; MARTINS, Renata Duval. Nova lei da imigraçáo no Brasil: o trabalhador estrangeiro diante do paradigma 
constitucional - fraternal. 24 jan. 2018. Disponível em: http://www.editorajc.com.br/ nova-lei-da-imigracao-no-brasil-o-trabalhador-estrangeiro-diante-do-paradigma-constitucional-fraternal/. Acesso em: 23 ago. 2019.

CULPI, Ludmila Andrzejewski. Nova lei de migraçóes brasileira: inspiração no modelo da lei migratória argentina? Disponível em: http://www.humanas.ufpr.br/portal/nepri/ files/2012/04/Nova-lei-de migra\%C3\%A7\%C3\%B5es-brasileira_Inspira\%C3\%A7\%C3\%A3o-no-modelo-da-lei-argentina.pdf. Acesso em: 22 ago. 2019.

DELFIM, Rodrigo Borges. Nova Lei de Migração: Mitos versus verdade. MigraMundo, on-line. São Paulo, 18 abr. 2017. Disponível em: http://migramundo.com/veja-sete-mitos-e-verdades-sobre-a-lei-de-migracao-em-debate-no-senado. Acesso em: 18 ago. 2019.

DEFENSORIA PÚBLICA DA UNIÃO (DPU). Uma introduçáo às migraçóes internacionais no Brasil contemporâneo. Módulo 2, p. 1 - 43. Disponível em: https:// www.justica.gov.br/seus-direitos/refugio/anexos/apostila-migracao-modulo-2.pdf. Acesso em: 20 dez. 2019.

EVANGELISTA, Rodrigo Luiz Soares. Os reflexos da imigração Venezuelana: perfil dos imigrantes, Segurança Pública e Saúde Pública. O defesanet, 2017, on-line. Brasília, 19 dez. 2017. Disponível em: http://www.defesanet.com.br/ven/noticia/27999/Os-reflexosda-imigracao-Venezuelana-perfil-dos imigrantes - Seguranca-Publica-e-Saude-Publica/. Acesso em: 18 ago. 2019.

FENACOM. Brasil é o país mais burocrático do mundo, segundo Banco Mundial. Folha de Londrina (PR), on -line. 2 fev. 2018. Disponível em: http://www.fenacon.org.br/ noticias/brasil-e-o-pais-mais-burocratico-do-mundo-segundo-banco-mundial-2963/.

FUNDAÇÃO GETÚlIO VARGAS. Diretoria de Análise de Políticas Públicas (DAPP). O Debate sobre a Lei de Migraçáo, on-line. Rio de Janeiro, 26 maio 2017, p. 1-16. Disponível em: http://bibliotecadigital.fgv.br/dspace/bitstream/handle/10438/18340/DAPP-Leide-Migra\%c3\%a7\%c3\%a3o-1.pdf?sequence=1\&isAllowed=y. Acesso em: 18 ago. 2019.

GUERRA, Sidney. A nova lei de migração no brasil: avanços e melhorias no campo dos direitos humanos. Revista de Direito da Cidade, vol. 09, no 4. ISSN 2317-7721 pp. 1717-1737. Disponível em: http://www.e-publicacoes.uerj.br/index.php/rdc/article/ viewFile/28937/21967. Acesso em: 19 ago. 2019.

A nova lei de migração no brasil: avanços e melhorias no campo dos direitos humanos. Revista de Direito da Cidade. Disponível em: http://www.e-publicacoes.uerj. br/index.php/rdc/article/viewFile/28937/21967. Acesso em: 19 ago. 2019.

.Direitos Humanos. Curso Elementar. 5a ed. São Paulo: Saraiva, 2017.

INSTITUTO MIGRAÇÓES E DIREITOS HUMANOS (IMDH). Glossário. Brasília, 31 jan. 2014. Disponível em: https://www.migrante.org.br/imdh/glossario/. Acesso em: 20 dez. 2019. 
LEITE, Carlos Alberto. Análise das Políticas Públicas para Refugiados no Brasil à luz da Nova Lei de Migraçáo: um Estudo de Caso nas Áreas de Saúde, Trabalho e Educação na regiấo metropolitana do Rio de Janeiro. 236 f. Dissertação (Mestrado em Políticas Públicas em Direitos Humanos) - Núcleo de Políticas Públicas em Direitos Humanos, Universidade Federal do Rio de Janeiro, Rio de Janeiro, 2019.

MAISONNAVE, Fabiano. Protesto em Roraima pede mais ordem na fronteira e assusta venezuelanos. Folha de Sáo Paulo, on-line. São Paulo, 17 ago. 2019. Disponível em: https://www1.folha.uol.com.br/mundo/2019/08/um-ano-apos-confronto-com-venezuelanos-moradores-brasileiros-protestam.shtml. Acesso em: 18 ago. 2019.

MAZZUOLI, Valério de Oliveira. Curso de Direito Internacional Público. 6a ed. São Paulo: Editora Revista dos Tribunais, 2012.

MILESI, Rosita. Por uma nova Lei de Migraçóes: a perspectiva dos direitos humanos. In: GREGORI, José et al. ACNUR. Refúgio. Migraçôes e Cidadania. Caderno de Debates 2. Agosto de 2007. IMDH, 2007.

MINISTÉRIO DO TRABALHO. Coordenadoria Geral de Imigração (CGIg). $2^{\circ}$ Trimestre 2018 (Abr-Jun). Autorizaçóes de residência concedidas a imigrantes. Disponível em: http://obmigra.mte.gov.br/index.php/relatorios-cgig-e-cnig. Acesso em: 20 ago. 2019.

MOULIN, Carolina; SANTORO, Maurício. Três mitos sobre refugiados. Observatório do amanhã, on-line. Rio de Janeiro. Disponível em: https://museudoamanha.org.br/pt -br/tres-mitos-sobre-refugiados. Acesso em: 18 ago. 2019.

NÚMERO DE REFUGIADOS E MIGRANTES DA VENEZUELA CHEGA A 4 MILHÓES. Agência Brasil, EBC, on-line. 07 jun. 2019. Disponível em: http://agenciabrasil.ebc.com.br/internacional/noticia/2019-06/numero-de-refugiados-e-migrantes-davenezuela-chega-4-milhoes. Acesso em 18 dez. 2019.

NOVO, Benigno Núñez. Migraçáo na visão da nova lei, on - line. Brasilia-DF: 03 abr. 2018. Disponivel em: https://conteudojuridico.com.br/consulta/Artigos/51509/migracao-na-visao-da-nova-Acesso em: 17 dez. 2019.

OLIVEIRA, Antônio Tadeu Ribeiro de. Nova lei brasileira de migração: avanços, desafios e ameaças. R. bras. Est. Pop., Belo Horizonte, v. 34, n.1, p.171-179, jan./abr. 2017. Disponível em: http://www.scielo.br/pdf/rbepop/v34n1/0102-3098-rbepop-34-01-00171. pdf. Acesso em: 12 ago. 2019.

RAMOS, André de Carvalho. Os avanços da nova Lei de Migração. Jornal da USP. São Paulo, 22 maio 2017. Disponível em: https://jornal.usp.br/atualidades/os-avancos-danova-lei-de-migracao/. Acesso em: 19 ago. 2019.

REDIN, Giuliana. Direito Humano de Imigrar e os desafios para construção de uma política nacional para imigrantes e refugiados. In: REDIN, Giuliana; SALDANHA, Jânia Maria Lopes; SILVA, Maria Beatriz Oliveira da. Direitos Emergentes na Sociedade Global: PPG em Direito na UFSM. Santa Maria: UFSM, 2016. 
RODRIGUES, Edílson. RR sofre com o aumento de crimes cometidos por imigrantes. Folha de Boa Vista, Boa Vista, 29 ago. 2019. Disponível em: https://folhabv.com.br/noticia/CIDADES/Capital/RR-sofre-com-o-aumento-de-crimes-cometidos-por-imigrantes/54433. Acesso em: 18 ago. 2019.

SCHREIBER, Mariana. Grave crise em Roraima justifica fechamento da fronteira? Entenda os argumentos contra e a favor. BBC, NEWS Brasil, on-line. Brasília, 22 ago. 2018. Disponível em: https://www.bbc.com/portuguese/internacional-45266973. Acesso em: 22 ago. 2019.

SILVA, Hugo Medeiros Gallo da. Imigração, vetor estratégico para o desenvolvimento e crescimento nacional. In: BRASIL. Presidência da República. Diálogos Estratégicos: migração e seus impactos na sociedade do século XXI. Vol 1, n. 4, Dez 2018. p. 14-17. Disponível em: http://www.secretariageral.gov.br/estrutura/secretaria_de_assuntos_estrategicos/publicacoes-e-analise/revista-dialogos-estrategicos/dialogosestrategicos-nr-4.pdf. Acesso em: 24 ago. 2019.

TORELLY, Marcelo (coord.) et al. Visóes do Contexto Migratório no Brasil. Brasília: Organização Internacional para as Migrações, Agência das Nações Unidas para as Migraçōes, 2017.

Política de refúgio do Brasil consolidada. Brasília: Organização Internacional para as Migraçôes, Agência das Nações Unidas para as Migraçóes, 2017.

ZORTEA, Gustavo. Migraçáo: nova lei assegura direitos e combate a discriminação. Disponível em: https://www12.senado.leg.br/noticias/especiais/especial-cidadania/migracao-nova-lei-assegura-direitos-e-combate-a-discriminacao. Acesso em: 18 ago. 2019. 